fowers. When mature, the stigma protrudes considerably beyond the indusium. This appears to differ entirely from what takes place in Lescitenanltia.

"I have recently been much interested with the curious irritability displased by the stigma of Glossostigma elatinoides, one of the Scrophularine?. The style is dilated towards its apex into a broad spoon-shaped stigma, which, when the flower expands, is closely doubled over the four stamens, entirely concealing them from view. If the front of the bent part of the style is touched it at once springs up, uncovering the stamens, and moves back to the upper lobe of the corolla, to which it becomes closely applied. In this position it remains for a few minutes, and then slowly moves back to the stamens and curves over them as at first. It appears to me that this irritability of the stigma is simply a contrivance to insure cross-fertilisation, for an insect crawling into the flower must inevitably touch the stigma, which rould then uncover the stamens. On withdrawing, the insect would be certain to dust itself with pollen, but it would not by this effect the fertilisation of the flower, for the stigma would be then closely applied to the upper lobe of the corolla, entirely out of its way. If the insect were, however, to visit another flower it is evident that it must come into contact with the stigma at its first entrance and would doubtless leave some pollen thereon. The movement of the stigma is remarkably rapid, and its apex must pass through an angle of at least I $S 0^{\circ}$. I have been unable to find a record of a similar case, or of so pronounced a degree of irritability in the stigma of any plant. The movement of the lobes of the stigma in Mimulus is much weaker, and is through a much less angle. Yours faithfully, "T. F, CHEESEMAN

"Charles Darwin Esq., F.R.S."

\section{A TELEPHONIC ALARUM}

THE speaking of the telephone is admittedly so weak 1 that it can only be caught by keeping the instrument in immediate contact with the ear. Hence there is transmitted through the telephone in its present form no sound which would be intense enough to announce to any one who was in a large rcom and who did not hold the telephone close to his ear, that a message was about to be sent from the transmitting station. The consequence is that a warning apparatus must be attached to the telephone, so that there may be no fear of missing a projected telephonic conversation.

It is clear that the conducting wire of a telephone can be used to sound a bell as an alarum by means of a current from a galvanic bat!ery, and thereby the defect referred to would be supplied. But the necessary apparatus would considerably raise the price of fitting up a telephore apparatus, and besides, one most important property of the telephone, viz., producing the required electric current automatically, would be partly lost. I have, then, invented another warning apparatus, which, I believe, is quite workable.

Hitherto telephones have been so constructed that only one pole ( $\mathrm{N}$ in the figure) of the magnet is effective; I now use also the second pole $S$, by providing it with a coil of wire, which is simply inserted in the circuit behind the first coil. (The dotted lines in the figure will explain this connection; the two ends $\alpha$ and $\beta$ are connected with the binding screws fastened to the telephone; from this the circuit goes to the second telephone.) Before this pole of the magnet may be very easily set up a tuningfork, A, which, with the telephone, is simply fixed -on a resonance case, $B$; this arrangement should be made both at the transmitting and receiving stations, and both forks should be in unison. If now the sending station wish to signal that a conversation is to be begun, the fork of that place will be sounded with a fiddle-bow; the currents thereby induced in the coil are powerful enough to set the fork of the receiving station in such intense vibration that the sound may be distinctly heard in a large room; warned by this signal a person can in the usual way put the telephone to his ear and listen to the words from the transmitting station. And so vice versâ.

I have made an experiment in a large room, when about 100 people were present, and all could hear the sounds of the fork, which in the manner described was set in vibration by a second fork in a distant room. The two forks were König $\mathrm{Ut}_{4}$; lower forks give less clearly heard tones; with higher forks I was unable to make any experiment, since I had not two similar ones at my disposal.

Let me mention two other experiments which I have made. The first is of importance in connection with the question as to how the clang-tints of tones are reproduced through the telephone. In one of the two telephones described substitute for the $\mathrm{Ut}_{4}$ fork a higher one, and sound this by means of a fiddle-bow, and there will be heard with another inserted telephone of the ordinary construction tones of even 12,000 double vibrations per second, a sign that the variations of the magnetic condition of a magnet perceptibly occur, even when the forces producing these variations change their size 24,000 times in

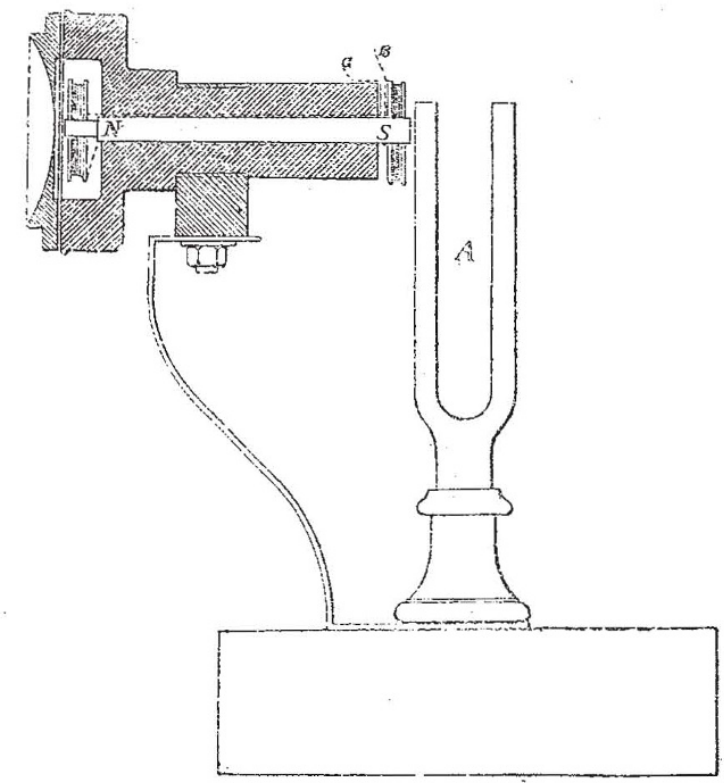

a second. This result moreover was not to be expected, since, as is known, magnetic polarisation requires time to accomplish. Whether these higher tones are comparatively weaker than the deeper cannot, be determined, but probably this is the case.

In another experiment I used the telephone to test the electric vibrations indiçated by Helmholtz and others, which are produced by the opening of the primary current of an induction apparatus in the induced coil, when the ends of the latter are connected with tho armatures of a condenser. For this purpose $I$ inserted the telephone in the circuit between coil and condenser, and observed the effect when the current in the inducing spiral was opened.

When the ends of the induced spiral were not connected with the condenser, I heard a dull report in the telephone; when, again, these ends were connected with the condenser, this report was accompanied by a shorter, higher sound, whose vibration-number might perhaps be determined by a musical ear; a proof of the existence of the vibrations mentioned in the last case. The obseryations were made with a telephone, the iron membrane of which was very thin and had a very deep tone.

W. C. RÖNTGEN 